\title{
Impact of Immediate Versus Delayed Post Abortion Family Planning Counseling on Increasing Contraceptive Rate at Beni Sueif General Hospital
}

\author{
Doaa Mohamed Thabet, Mahmoud Ahmed Mahmoud Abdel-Aleem, Ghadah Abdelrahman Mahmoud \\ Inspector of Nursing Schools of Beni sueif Governorate, \\ Assistant Professor of Obstetrics \& Gynecology, Faculty of Medicine, Assiut University, \\ Assistant Professor of Obstetrics and Gynecological Nursing, Faculty of Nursing, Assiut University.
}

\begin{abstract}
Abortion is the termination of a pregnancy by the removal or expulsion of an embryo or fetus from the uterus, resulting in or caused by its death. The aim of this study: Assess the impact of Immediate Versus Delayed Post Abortion Family Planning Counseling on Increasing Contraceptive Rate Subjects and method: All the included Post abortion women were randomly assigned into two main groups, Intervention Group women was counseled immediately after abortion about the family planning methods. The Control Group women who were receive the same counseling information but after one week of abortion at the Out Patient Family Planning Clinics.

Results: The majority of both groups had no pregnancy with using family planning methods "79.0\%\&79.5\%" respectively, with sig, differences between both groups P.V (0.040). Conclusion: There is Sig. differences with P.V (0.001) between Intervention and Control group as regards to the rate of contraceptive use. So Delayed is better than Immediate post abortion Family Planning Counseling on Increasing Contraceptive Rate. Recommendations: Public health promotion programs approved by the Ministry of Health should promote child-spacing, modern methods of contraception.
\end{abstract}

\section{Key words: Abortion, Counseling, Family Planning \&Methods.}

\section{Introduction}

Post abortion clients are women and girls with a clear need for family planning. Even if a woman wants to have a child immediately, WHO guidelines recommend she wait at least six months after an abortion before getting pregnant again (WHO, 2006). Two hundred five million pregnancies each year worldwide, 80 million of them are unplanned. Of these, 42 million are terminated -22 million legally and 20 million illegally (WHO, 2007).

Unsafe abortion accounts for $13 \%$ of maternal deaths worldwide and as much as $25 \%$ in some countries such as "West Africa" . Deaths related to unsafe abortion in developing regions are estimated as high as 100 deaths per 100,000 abortions in Latin America, 400 deaths per 100,000 abortions in Asia, and 600 deaths per 100,000 abortions in Africa (Sedgh, et al., 2007).

The WHO estimates that in Africa, one in seven maternal deaths result from unsafe abortion. About 1.7 million women in the region are hospitalized annually for treatment of complications of unsafe abortion (WHO, 2007).

In 2008, nearly all abortions in Africa were unsafe (Sedgh et al., 2012) and $41 \%$ of unsafe abortions in developing regions were among young women ages 15 to 24 years (Shah and Ahman, 2012).

Egypt Demographic Health Survey suggests that onethird had attempted to terminate a pregnancy. Other studies suggest that about one-third of abortions are carried out without medical supervision, with women trying traditional remedies or overdoses of aspirin or quinine, at a risk to their own lives (EDHS, 2008).

Significance of the study: Effective linkage between post abortion care services (PAC) and family planning is essential for reducing the incidence of repeat unwanted pregnancy and unsafe abortion (Population Council and Family Health International, 2007) : It was estimated that one in five admissions to the Obstet./Gyn ward is for treatment of abortion complications, In a study conducted under Asia and Near East Operations Research Technical Assistance Project in Egypt, so abortion (spontaneous or induced) constitutes a public health problem in Egypt. (Population Council and Family Health International, 2007).

In 2010 ,The total number of abortion women in Beni-suief General Hospital was (930) cases ,more recent data from 2011 show elevation to (1000) case until now, so the rate is increased with $7 \%$ of cases (Obstet. \&Gyn. Department, Hospital Data Base, 2011).

\section{Aim of the study}

Assess the impact of Immediate Versus Delayed Post Abortion Family Planning Counseling on Increasing Contraceptive Rate at Beni Sueif General Hospital. 


\section{Subjects and methods}

\section{Research Design}

Randomized controlled trial was used in this study to compare the effect of using immediate versus delayed Post abortion Family Planning Counseling as a method for increasing contraceptive use.

Setting: The study was carried out at post partum ward and Family Planning Clinics, Beni-suief General Hospital. This hospital received approximately 1000 cases of abortion annually. The Obstetric Department has 25 nurses and 2 supervisors.

\section{Sample}

It was calculated by sample size equation. Sample size estimation was based on the following parameters. The presumed difference between study and control groups "the presumed benefit from counseling" was around $20 \%$, alpha- $5 \%$, beta, $80 \%$. So the calculated sample size was (210) in either group.

\section{Intervention}

Counseling Place and time:-At Post abortion ward (Immediately).At the Outpatient Family Planning Clinic (After 1week).All the included Post abortion women were randomly assigned into two main groups, women in each: Group (A): Intervention Group (210) women was counseled immediately after abortion. (After $6 \mathrm{hrs}$ ) about the family planning methods. The researcher emphasized the importance of educating post abortion women about the family planning methods, their advantages and disadvantages and the suitable methods for them. Women were also counseled about the referral system for using the family planning method at the Out Patient Family Planning and the time of visit. Group (B): The Control Group (210) women who were receive the same counseling information but after one week of abortion at the Out Patient Family Planning Clinics.

\section{Randomization}

Randomization was done using computer-generated random table. After acceptance of eligible women to participate in the study, they was assigned randomly to either one of the above groups .Allocation concealment was done using serially-numbered closed opaque envelope. Counseling for participation was done before recruitment. Once allocation had been done, it could not be changed.

\section{Pilot Study}

A pilot study was carried out to assess the expected difference between study group and control group to test the feasibility and clarify the study tool. The sample of pilot study was (42) women were excluded from the total sample. The necessary modification was done if needed.

\section{Ethical Considerations}

An official permission was obtained from the Dean of the Faculty of Nursing to the administration of BeniSuief General Hospital. 


\section{Result}

Part I: Socio demographic characteristics of the post aborted women

Table (1): Distribution of women according to Sociodemographic characteristics.

\begin{tabular}{|c|c|c|c|c|c|}
\hline \multirow[b]{2}{*}{ Sociodemographic characteristics } & \multicolumn{2}{|c|}{ Intervention Group } & \multicolumn{2}{|c|}{ Control group } & \multirow[b]{2}{*}{ P. value } \\
\hline & $\begin{array}{c}\text { Frequency } \\
(\mathbf{n = 2 0 0})\end{array}$ & Percentage $\%$ & $\begin{array}{c}\text { Frequency } \\
(\mathbf{n = 2 0 0 )}\end{array}$ & $\begin{array}{c}\text { Percentage } \\
\%\end{array}$ & \\
\hline 1.Age $\left(\right.$ Mean $^{ \pm}$SD) & \multicolumn{2}{|c|}{$26.6 \pm 6.7$} & \multicolumn{2}{|c|}{$26.4+5.9$} & 0.924 \\
\hline$\bullet \leq 20$ year & 17 & 8.5 & 18 & 9 & \multirow{6}{*}{0.939} \\
\hline - (20-25) year & 86 & 43 & 84 & 42 & \\
\hline - (26-30) year & 45 & 22.5 & 51 & 25.5 & \\
\hline - $(31-35)$ year & 27 & 13.5 & 26 & 13 & \\
\hline$\cdot \geq 36$ year & 25 & 12.5 & 21 & 10.5 & \\
\hline - Total & 200 & 100.0 & 200 & 100.0 & \\
\hline \multicolumn{6}{|l|}{ 2.Residence } \\
\hline - Rural & 134 & 67 & 144 & 72 & \multirow{3}{*}{0.277} \\
\hline - Urban & 66 & 33 & 56 & 28 & \\
\hline - Total & 200 & 100.0 & 200 & 100.0 & \\
\hline \multicolumn{6}{|l|}{ 3.Education } \\
\hline - illiterate & 102 & 51 & 102 & 51 & \multirow{7}{*}{0.951} \\
\hline - R \& W & 31 & 15.5 & 29 & 14.5 & \\
\hline - Primary & 2 & 1 & 3 & 1.5 & \\
\hline - Preparatory & 3 & 1.5 & 5 & 2.5 & \\
\hline - Secondary & 56 & 28 & 53 & 26.5 & \\
\hline - University & 6 & 3 & 8 & 4 & \\
\hline - Total & 200 & 100.0 & 200 & 100.0 & \\
\hline \multicolumn{6}{|l|}{ 4.Occupation } \\
\hline - Employer & 6 & 3 & 4 & 2 & \multirow{3}{*}{0.522} \\
\hline - House Wife & 194 & 97 & 196 & 98 & \\
\hline - Total & 200 & 100.0 & 200 & 100.0 & \\
\hline
\end{tabular}

Part II Obstetric History of the post aborted women

Table (2): Distribution of women according to their Obstetric History.

\begin{tabular}{|c|c|c|c|c|c|}
\hline \multirow{2}{*}{ Obstetric History } & \multicolumn{2}{|c|}{ Intervention Group } & \multicolumn{2}{|c|}{ Control group } & \multirow{2}{*}{ P. value } \\
\hline & Frequency $(n=200)$ & Percentage $\%$ & Frequency $(n=200)$ & Percentage \% & \\
\hline Gravidity & \multicolumn{2}{|c|}{$2.5+1.5$} & \multicolumn{2}{|c|}{$2.6+1.5$} & 0.451 \\
\hline $1-3$ & 158 & 79 & 159 & 79.5 & \multirow{2}{*}{0.165} \\
\hline$\geq 4$ & 42 & 21 & 41 & 20.5 & \\
\hline Total & 200 & 100 & 100 & 200 & \\
\hline Parity & \multicolumn{2}{|c|}{$\neq 2.2 \pm 1.3$} & \multicolumn{2}{|c|}{$2.2 \pm 1.2$} & 0.729 \\
\hline 0 & 1 & 0.5 & 4 & 2.0 & \\
\hline $1-3$ & 171 & 85.5 & 165 & 82.5 & \multirow{2}{*}{0.451} \\
\hline$\geq 4$ & 28 & 14 & 31 & 15.5 & \\
\hline Total & 200 & 100 & 100 & 200 & \\
\hline Abortion & \multicolumn{2}{|c|}{$\neq 1.3+0.6$} & \multicolumn{2}{|c|}{$1.4+0.7$} & 0.179 \\
\hline 0 & 153 & 76.5 & 141 & 70.5 & \multirow{2}{*}{0.493} \\
\hline $1-4$ & 47 & 23.5 & 59 & 29.5 & \\
\hline Total & 200 & 100 & 100 & 200 & \\
\hline
\end{tabular}




\begin{tabular}{|c|c|c|c|c|c|}
\hline \multirow{2}{*}{ Obstetric History } & \multicolumn{2}{|c|}{ Intervention Group } & \multicolumn{2}{|c|}{ Control group } & \multirow{2}{*}{ P. value } \\
\hline & Frequency $(n=200)$ & Percentage \% & Frequency $(n=200)$ & Percentage $\%$ & \\
\hline Still Birth & \multicolumn{2}{|c|}{$\neq 1.3+0.5$} & \multicolumn{2}{|c|}{$1.1+0.3$} & 0.246 \\
\hline 0 & 188 & 94 & 187 & 92.5 & \multirow{3}{*}{0.489} \\
\hline $1-2$ & 12 & 6 & 13 & 6.5 & \\
\hline Total & 200 & 100 & 100 & 200 & \\
\hline Neonatal. Death & \multicolumn{2}{|c|}{$\neq 1.1 \pm 0.3$} & \multicolumn{2}{|c|}{$1.0 \pm 0.0$} & 0.071 \\
\hline 0 & 189 & 94.5 & 191 & 95.5 & \multirow{3}{*}{0.456} \\
\hline $1-2$ & 11 & 5.5 & 9 & 4.5 & \\
\hline Total & 200 & 100 & 100 & 200 & \\
\hline Living Child & $2.1+1.2$ & $2.1+1.1$ & 0.616 & Living Child: & $2.1+1.2$ \\
\hline 0 & 1 & 0.5 & 4 & 2.0 & \multirow{4}{*}{0.961} \\
\hline $1-3$ & 174 & 87 & 174 & 87 & \\
\hline$\geq 4$ & 25 & 12.5 & 22 & 11.0 & \\
\hline Total & 200 & 100 & 100 & 200 & \\
\hline Male & $1.02 \pm 0.85$ & $1.09 \pm 0.84$ & 0.408 & & \multirow{4}{*}{0.567} \\
\hline 0 & 57 & 30 & 40 & 20 & \\
\hline $1-4$ & 143 & 70 & 160 & 80 & \\
\hline Total & 200 & 100 & 100 & 200 & \\
\hline Female & $1.02 \pm 0.89$ & $1.01 \pm 0.89$ & 0.911 & & \multirow{4}{*}{0.907} \\
\hline 0 & 60 & 30 & 64 & 32 & \\
\hline $1-4$ & 140 & 70 & 136 & 68 & \\
\hline Total & 200 & 100 & 100 & 200 & \\
\hline \multicolumn{6}{|l|}{ Previous Delivery } \\
\hline C.S & 60 & 30 & 58 & 29.0 & \multirow{4}{*}{0.386} \\
\hline N.V & 139 & 59.5 & 138 & 69.0 & \\
\hline $\mathrm{NO}$ & 1 & 0.5 & 4 & 2.0 & \\
\hline Total & 200 & 100.0 & 200 & 100.0 & \\
\hline
\end{tabular}

Part III: History of Family Planning Methods

Table (3): Distribution of women according to History of Family Planning Methods.

\begin{tabular}{|c|c|c|c|c|c|}
\hline \multirow{2}{*}{$\begin{array}{c}\text { History of Family Planning } \\
\text { Methods }\end{array}$} & \multicolumn{2}{|c|}{ Intervention Group } & \multicolumn{2}{|c|}{ Control group } & \multirow{2}{*}{$\begin{array}{c}P . \\
\text { value }\end{array}$} \\
\hline & $\begin{array}{l}\text { Frequency } \\
(\mathbf{n}=\mathbf{2 0 0})\end{array}$ & $\begin{array}{c}\text { Percentage } \\
\%\end{array}$ & $\begin{array}{l}\text { Frequency } \\
(\mathbf{n}=\mathbf{2 0 0})\end{array}$ & $\begin{array}{c}\text { Percentage } \\
\%\end{array}$ & \\
\hline \multicolumn{5}{|l|}{ 1.Use of F.P.M } & \multirow{5}{*}{0.892} \\
\hline Yes & 167 & 83.5 & 168 & 84 & \\
\hline NO & 33 & 16.5 & 32 & 16 & \\
\hline Total & 200 & 100.0 & 200 & 100.0 & \\
\hline \multicolumn{5}{|l|}{ 2.Last F.P.M } & \\
\hline Injection & 19 & 9.5 & 13 & 6.5 & \multirow{7}{*}{0.502} \\
\hline I.U.D & 72 & 36 & 76 & 38 & \\
\hline Natural Contraceptive's Method & 10 & 5 & 19 & 9.5 & \\
\hline Norplant & 1 & 0.5 & 1 & 0.5 & \\
\hline Pills & 65 & 32.5 & 59 & 29.5 & \\
\hline $\mathrm{NO}$ & 33 & 16.5 & 32 & 16 & \\
\hline Total & 200 & 100.0 & 200 & 100.0 & \\
\hline
\end{tabular}




\begin{tabular}{|c|c|c|c|c|c|}
\hline \multirow{2}{*}{$\begin{array}{c}\text { History of Family Planning } \\
\text { Methods }\end{array}$} & \multicolumn{2}{|c|}{ Intervention Group } & \multicolumn{2}{|c|}{ Control group } & \multirow{2}{*}{$\begin{array}{c}P . \\
\text { value }\end{array}$} \\
\hline & $\begin{array}{l}\text { Frequency } \\
\qquad(\mathbf{n}=\mathbf{2 0 0})\end{array}$ & $\begin{array}{c}\text { Percentage } \\
\%\end{array}$ & $\begin{array}{l}\text { Frequency } \\
\quad(\mathbf{n}=\mathbf{2 0 0})\end{array}$ & $\begin{array}{c}\text { Percentage } \\
\%\end{array}$ & \\
\hline \multicolumn{6}{|c|}{ 3.Causesof Discontinuation of F.P.M } \\
\hline Desire of husband & 19 & 9.5 & 25 & 12.5 & \multirow{6}{*}{0.778} \\
\hline Side effect & 46 & 23 & 43 & 21.5 & \\
\hline To get pregnant & 80 & 40 & 73 & 36.5 & \\
\hline Others & 22 & 11 & 27 & 13.5 & \\
\hline $\mathrm{NO}$ & 33 & 16.5 & 32 & 16 & \\
\hline Total & 200 & 100.0 & 200 & 100.0 & \\
\hline
\end{tabular}

Part IV: The current condition

Table (4): Distribution of women according to the current condition.

\begin{tabular}{|c|c|c|c|c|c|}
\hline \multirow{2}{*}{ The current condition } & \multicolumn{2}{|c|}{ Intervention Group } & \multicolumn{2}{|c|}{ Control group } & \multirow[b]{2}{*}{ P. value } \\
\hline & $\begin{array}{c}\text { Frequency } \\
(n=200)\end{array}$ & $\begin{array}{c}\text { Percentage } \\
\%\end{array}$ & $\begin{array}{c}\text { Frequency } \\
(\mathbf{n = 2 0 0 )}\end{array}$ & $\begin{array}{c}\text { Percentage } \\
\%\end{array}$ & \\
\hline 1. Gestational age.(Weeks) & \multicolumn{2}{|c|}{$10.1 \pm 2.9$} & \multicolumn{2}{|c|}{$10.4 \pm 3.1$} & 0.342 \\
\hline $5-10$ & 122 & 61 & 122 & 61 & \\
\hline $11-15$ & 66 & 33 & 64 & 32 & 0.911 \\
\hline $16-20$ & 12 & 6 & 14 & 7 & \\
\hline Total & 200 & 100.0 & 200 & 100.0 & \\
\hline \multicolumn{6}{|l|}{ 2.Type of abortion } \\
\hline Induced & 8 & 4 & 8 & 4 & \multirow{6}{*}{0.945} \\
\hline Inevitable & 5 & 2.5 & 6 & 3 & \\
\hline Incomplete & 177 & 88.5 & 177 & 88.5 & \\
\hline Missed & 8 & 4 & 8 & 4 & \\
\hline Spontaneous & 1 & 0.5 & 0 & 0 & \\
\hline Complete & 1 & 0.5 & 1 & 0.5 & \\
\hline Total & 200 & 100.0 & 200 & 100.0 & \\
\hline \multicolumn{6}{|l|}{ 3.Method of evacuation } \\
\hline $\mathrm{D} \& \mathrm{C}$ & 196 & 98 & 194 & 97 & \multirow{3}{*}{0.775} \\
\hline Suction & 1 & 0.5 & 1 & 0.5 & \\
\hline Others & 3 & 1.5 & 5 & 2.5 & \\
\hline Total & 200 & 100.0 & 200 & 100.0 & \\
\hline
\end{tabular}

Part V: Follow up

Table (5): Distribution of women according to using of Family Planning Method.

\begin{tabular}{|c|c|c|c|c|c|}
\hline \multirow{2}{*}{ Follow up } & \multicolumn{2}{|c|}{ Intervention Group } & \multicolumn{2}{|c|}{ Control group } & \multirow[b]{2}{*}{ P. value } \\
\hline & $\begin{array}{c}\text { Frequency } \\
\quad(\mathbf{n = 2 0 0})\end{array}$ & $\begin{array}{c}\text { Percentage } \\
\%\end{array}$ & $\begin{array}{c}\text { Frequency } \\
(\mathbf{n = 2 0 0 )}\end{array}$ & $\begin{array}{c}\text { Percentage } \\
\%\end{array}$ & \\
\hline Missed cases & 4 & 2 & 25 & 12.5 & \multirow{4}{*}{0.001} \\
\hline Never using method & 18 & 9 & 8 & 4 & \\
\hline Stop using method & 20 & 10 & 2 & 1 & \\
\hline Yes still using & 158 & 79 & 165 & 82.5 & \\
\hline Total & 200 & 100.0 & 200 & 100.0 & \\
\hline
\end{tabular}


Table (6): Distribution of women according to Side effects of Family Planning Methods

\begin{tabular}{|l|c|c|c|c|c|}
\hline \multirow{2}{*}{ Follow up } & \multicolumn{2}{|c|}{ Intervention Group } & \multicolumn{2}{c|}{ Control group } \\
\cline { 2 - 6 } \\
\cline { 2 - 6 } value
\end{tabular}

Table (7): Distribution of women according to the way of using contraceptive method after counseling.

\begin{tabular}{|c|c|c|c|c|c|}
\hline \multirow[b]{2}{*}{ Follow up } & \multicolumn{2}{|c|}{ Intervention Group } & \multicolumn{2}{|c|}{ Control group } & \multirow[b]{2}{*}{$\begin{array}{c}\text { P. } \\
\text { value }\end{array}$} \\
\hline & $\begin{array}{c}\text { Frequency } \\
(n=178)\end{array}$ & $\begin{array}{c}\text { Percentage } \\
\%\end{array}$ & $\begin{array}{c}\text { Frequency } \\
(n=167)\end{array}$ & $\begin{array}{c}\text { Percentage } \\
\%\end{array}$ & \\
\hline Failure of using method & 20 & 11.2 & 8 & 4.8 & \multirow{2}{*}{0.001} \\
\hline Success/correct use of the method & 158 & 88.8 & 159 & 95.2 & \\
\hline Total & 178 & $\mathbf{1 0 0 . 0}$ & 167 & 100.0 & \\
\hline
\end{tabular}

Table (8): Distribution of women according to the occurrence of pregnancy.

\begin{tabular}{|c|c|c|c|c|c|}
\hline \multirow[b]{2}{*}{ Follow up } & \multicolumn{2}{|c|}{ Intervention Group } & \multicolumn{2}{|c|}{ Control group } & \multirow[b]{2}{*}{ P. value } \\
\hline & $\begin{array}{c}\text { Frequency } \\
(n=200)\end{array}$ & $\begin{array}{c}\text { Percentage } \\
\%\end{array}$ & $\begin{array}{c}\text { Frequency } \\
(n=200)\end{array}$ & $\begin{array}{c}\text { Percentage } \\
\%\end{array}$ & \\
\hline \multicolumn{6}{|l|}{ 4.Occurance of pregnancy } \\
\hline No pregnancy with used method & 158 & 80.6 & 159 & 90.9 & \multirow{4}{*}{0.040} \\
\hline No pregnancy without used method & 12 & 6.1 & 5 & 2.8 & \\
\hline Yes pregnancy with used method & 20 & 10.2 & 8 & 4.6 & \\
\hline Yes pregnancy without used method & 6 & 3.1 & 3 & 1.7 & \\
\hline Total & 196 & 100.0 & 175 & 100.0 & \\
\hline
\end{tabular}

Table (1): shows that less than half of the women at both groups are in the age group between 20-25 years $(43.0 \% \& 42 \%)$ respectively. More than two thirds of people in both groups are from rural area $(67.0 \% \& 72.0 \%)$ respectively. Whereas more than half of women of both groups are illiterate $(51.0 \% \& 51.0 \%)$ respectively. While the majority of the both groups are house wives $(97.0 \% \& 98 \%)$ respectively.

Table (2) : Concerning Obstetric history, table 2 indicates that the majority of the women at both groups were multigravida "79.0\%\&79.5\%" respectively. The mean of gravidity was $2.5 \pm 1.5 \& 2.6 \pm 1.5$ respectively. As for parity, majority of the women were had a previous history of 1-3 deliveries " $85.5 \% \& 82.5 \%$ " respectively. The mean of parity was $2.2 \pm 1.3 \& 2.2 \pm 1.2$ respectively. Majority of the women had no history of previous abortion "76.5\%\&70.5\%" respectively. The mean of abortion was $1.3 \pm 0.6 \& \quad 1.4 \pm 0.7$ respectively. Concerning history of previous labors, two third of the women at both groups were had a previous history of normal vaginal delivery "59.5\%\&69.0\%" respectively. One third of women at both groups were had a previous history of Cesarean Section"30.0\%\&29.0\%" respectively.

Concerning the use of family planning methods, Table (3) : show that the majority of both groups were using family planning methods" $83.5 \% \& 84.0 \% "$ respectively. More than one third of both groups were using I.U.D "36.0\%\&38.0\%" respectively, while the use of pills represents one third of them "32.5\%\&29.5\%" respectively. Concerning the cause of discontinuation of F.P.M, more than one third at both groups mentioned to get pregnant "40.0\%\&36.5\%" respectively.

Table (4): Concerning the current condition, table (4) show that nearly two thirds of both groups are (5-10) weeks of Gestation "61.0\%\&61.0\%" respectively. Concerning the type of abortion, the majority of both groups are incomplete abortion "88.5\&88.5\%\%" respectively. The vast majority of both groups have Dilatation and Curettage (D\&C) "98.0\%\&97.0\%" respectively. Concerning the desire of use F.P.M, the vast majority of them were accepted to participate in the study "96.0\%\&96.0\%" respectively. 
Table (5): This table shows that participants who still continue on F.P.M were significantly higher in Control group P. value 00.01 .

Table (6) : shows that about two thirds of both groups have no side effects from F.P.M"63.5\% \& $61.0 \% "$ respectively with no significant between both group P. value (0.44).

Table (7) : shows that using F.P.M correctly was significantly higher in Control group P. value 0.001 .

Table (8) : shows that the majority of both groups had no pregnancy with using family planning methods "79.0\%\&79.5\%" respectively, with sig, differences between both groups P.V (0.040).

\section{Discussion}

In the present study, nearly half of women $(43.0 \%$ \& $42 \%)$ in the intervention \&control groups respectively were in (20-25) year category of age.

This findings is supported by Ahmed (2006) who shows in her study about \{Effect of husband counseling toward female contraceptive methods in Assuit City \}, And Hassan (2011) who reported in her study about \{Emergency contraception as a backup of Lactational Amenorrhea method of Contraception that was mean age in both the control and intervention groups was in the young age category, While Youssef et al., (2007) reported $(39.1 \%$ \& $32.8 \%)$ in age groups (20-30) year.

This findings is against with this Ferreira et al., (2010) that was "82.7\%" of (20-39) category, and Ceylan et al., (2009) that is $23.2 \%$ in (20-24) category.

Almost half of women in this sample $(51 \%)$ were illiterate with no significant difference in women of both groups as regards the level of education.

This finding was supported by Shaaban and Glasier (2008) who reported that the study participants were predominantly illiterate. Ceylan et al., (2009) and Youssef et al., (2007) reported in their studies about \{Linking family planning with post abortion services in Egypt: Testing the feasibility, acceptability and effectiveness of two models of integration $\}$ that about half of the sample were illiterate.

However, in disagreement with this, Ahmed (2006) reported that $(80.0 \%)$ in both groups were read \& write. Afifi (2007) Ferreira et al., (2010) Hassan (2011) who reported in their studies that half of women were in secondary level of education .While, Prata et al., (2011) reported that $75.0 \%$ of the sample had secondary education or above.

According to the present study, the majority of women in the sample $(97.0 \%$ \& 98.0\%) in intervention \&control groups respectively were housewives.

Similar findings were reported by Ahmed (2006) Tilley, et al., (2009) and Hassan (2011) who noted in their studies in Egypt that the vast majority of the study participants were housewives. Azmat et al., (2012) found that $(83.9 \%)$ of the sample were housewives.

However, in disagreement with this, Ferreira et al., (2010) reported in their study about \{Choices on contraceptive methods in post abortion family planning clinic in the northeast Brazil that half of the sample were employed, Biney, (2011) who reported in her study about Exploring Contraceptive Knowledge and use among Women experiencing induced abortion in the greater Accra Region ,Ghana that $82.6 \%$ of the sample were employed. According to the present study, about two thirds of the women $(67.0 \% \& 72.0 \%)$ in intervention \&control groups respectively were living in rural area.

Similar findings were reported by Ahmed, (2006) Shaheen et al., (2007) Tilley, et al., (2009) Abdel Fattah (2011), and Hassan (2011) who noted that the vast majority of the study participants were living in rural areas. The majority of women in this study had no previous history of abortion $(76.5 \% \& 70.5 \%)$ for intervention \&control groups respectively. Similar findings were reported by Youssef et al., (2007) that $(64.1 \% \& 64.5 \%)$ of intervention \&control groups of the sample had no previous abortion, Ceylan et al., (2009) who reported in their study about \{Post abortion family planning counseling as a tool to increase contraception use that $(73.4 \%)$ of the sample had no previous abortion , Ferreira et al ., (2010) who reported that (73.4\%) of the sample had no previous abortion , Prata et al., (2011) also reported that just $30.0 \%$ of the sample had previous abortion.

However, in disagreement with this , Savelieva et al., (2003) reported in their study about \{Post abortion family planning operations research study in perm, Russia $\}$ is about $71.7 \%$ of intervention I, intervention II\& control groups had a previous history of abortion and Biney (2011) that the majority of the sample had a previous history of abortion. The present study showed that the majority of the women "83.5\% \& $84.0 \% "$ respectively of both groups used family planning methods previously.

This result is supported by Jackson et al., (2003) Ahmed ( 2006) who reported that $(76.0 \%$ \& $77.0 \%)$ respectively in both groups of women were previously used family planning methods and Hassan (2011) who reported that more than half of the sample used contraceptive methods before.

In disagreement with this, Savelieva et al., (2003) reported in their study that $90.0 \%$ of the total groups had never used contraceptive methods before; While Youssef et al., (2007) who reported that $(62.8 \%$ \& $54.7 \%$ ) respectively in both the groups women were previously never used family planning methods 
before. Ceylan et al., (2009) reported that 55.3\% had not used contraceptive methods and Ferreira et al., (2010) who reported that $(68.6 \%)$ of the sample had not used of family planning methods previously.

According to the present study, more than one third of two groups "36\% \& $38 \%$ " respectively were using I.U.D and nearly one third of sample "32.5\% \& $29.5 \% "$ respectively of both groups were using pills.

These findings are in agree with Ferreira et al., (2010) who reported that "15.4\%" of the women were using oral contraceptive , while Prata et al., (2011) reported that "55.0\%" of the women were using pill . Opoku (2012) reported in his statistical study about \{Contraceptive preferences of post- abortion patients in Ghana\} that "25.0\%" of women were used oral contraceptives. In disagreement with this, Matthew et al., (2008) reported that "20.0\%" of the women were not used I.U.D, Ceylan et al., (2009) reported that no women with no I.U.D. Azmat et al., (2012) who reported in his study about \{Post-abortion care family planning use in Pakistan $\}$ that "7.1\%" of the women used pills and no women used I.U.D method.

The current study showed also the main reason for family planning discontinuation of the women was to get pregnant which is "40.0\% \& 36.5\%" in intervention \&control groups respectively.

Similar findings were reported by Savelieva et al., (2003) who mentioned that "57.8\%" of the women had a planning to have children in the future, Ahmed (2006) who reported that "87.0\%" of the women did not use a family planning method to get pregnant, while Youssef et al., (2007) reported that "69.4\%" of the women wanted to have more children.

In disagreement with this, Ceylan et al., (2009) shows that "68.4\%" of the women wanted to stop childbearing and "31.6\%" of them were planning to postpone childbearing. Khanal et al., (2011) who reported in their study about \{Practices and perceptions on contraception acceptance among clients availing safe abortion services in Nepal\} that "48.0\%" of the women stop continuation of the family planning methods due to their side effects.

The present study showed that the majority of the women"77.5\% \&82.5\%" respectively of both groups is still continuing the use of F.P.M with highly significant $(0.001)$ of two groups .

These finding is supported by Ahmed (2006) who shows that increase the continuation rate of family planning use after counseling was " $84.0 \% "$. Ceylan et al., (2009) reported in their study that "75.9\%" of women had high contraception usage rate and Ferreira et al ., (2010) who reported in her statistical study that "97.4\%" of the women accepted at least one contraceptive method .

Similar findings were reported by Prata et al., (2011) shows in her study that "86.0\%" of women used post abortion contraceptive method, while Khanal et al.,
(2011) shows that "91.0\%" are acceptable the F.P.M counseling. Abdel Fattah et al., (2011) shows that "53.0\%" of the women had post abortion contraceptive use, Similar findings were reported by Hassan, (2011) who shows that "53.9\%" of the women used contraceptive methods during follow up period, while Prata (2011) shows that "57.0\%" of the women were using contraceptive methods. Azmat et al., (2012) shows that "72.9\%" of the women had post abortion contraceptive use, while Opoku, (2012) shows that "68.0\%" of the sample had high acceptance rate of contraception following counseling. In contrast, Savelieva et al., (2003) mentioned that "62.0\%\&67.0\%" of intervention I\& control groups were not continued the methods, Fasubaa (2004) reported that "54.0\%" of the women were not continued the methods, While Langston et al., (2010) reported in their study about $\{$ Structured contraceptive counseling-A randomized controlled trial \} that "56.0\%" of the women were not chose any method. The present results have also revealed that "63.5\%\&61.0\%" respectively of both groups did not complain from any side effects from using family planning methods.

This is supported by Ahmed (2006) who reported that "88.5\%" not complained from any side effects from using Family Planning Methods. In contrast with Hassan (2011) who shows that "59.8\%" of the sample complained of side effects to the usage of F.P.M. The present study shows that "89.0\% \&95\% "of the intervention \&control groups used the F.P.M correctly but the control group was significantly higher than intervention group P. Value (0.001). This is supported by Savelieva et al., (2003) that only "84.1\%\&79.2\%" respectively of the sample had no pregnancy after 12 month of abortion. In contrast with Fasubaa, (2004) shows that "51.0\%" of the sample were pregnant in the follow up period.

The present study shows that more than quarter of both groups had Continuation of using Family Planning Methods inconsistently "35.0\%\&25.0\%" respectively of both groups as regards the reason of F.P.M failure,

The present study shows that the majority "79.0\% \&79.5\%" respectively of both groups did not get pregnant with the used method in the period of follow up.This finding is supported by Savelieva et al., (2003) shows in that only "84.1\%\&79.2\%" respectively of the sample had no pregnancy after 12 month of abortion, while Ferreira et al ., (2010) and Hassan (2011) that shows "97.0\%" had no pregnancy.

In contrast with Fasubaa (2004) shows that "51.0\%" of the sample were pregnant in the follow up period. In this study there is about "2.0\%\&12.5\%" respectively from the total sample were missed cases. 
The majority of missed cases from Control group due to Commitment of appointments from the women.

\section{Conclusions}

In the light of the present study findings, it can be concluded that the main reason for family planning discontinuation is the desire of pregnancy which is " $40.0 \%$ \& $36.5 \% "$ respectively of both groups. It can also be concluded that more qualified counseling techniques including proper communication skills is required in post abortion period. There is Sig. differences with P.V (0.001) between Intervention and Control group as regards to the rate of contraceptive use. So Delayed is better than Immediate post abortion Family Planning Counseling on Increasing Contraceptive Rate.

\section{Recommendations}

1. Public health promotion programs approved by the Ministry of Health should promote child-spacing, modern methods of contraception and the risks of unsafe abortion.

2. Educational programs should be designed to participate in increasing post abortion contraceptive use and reduce the rate of unwanted pregnancy.

3. New studies should be established to increase the rate of post abortion contraceptive use.

4. All post-abortion women should receive voluntary post abortion family planning counseling.

\section{References}

1. Abdel Fattah, H., Mohamed, A., and Ebraheem, O., (2011): Post Abortion Family Planning Counseling as a tool to Increase Use of Family Planning Methods in El Minia City. Thesis of Fulfillment of Master Degree. Faculty Of Medicine. El Minia University.ch (3), Pp 134.

2. Afifi, M., (2007): Lactational amenorrhoea method for family planning and women empowerment in Egypt. Thesis of Fulfillment of Doctorate Degree. Singapore Medical Journal, 48(8), 758-762.

3. AGI, Curtis, C., Huber, D., and Moss-Knight, D., (2008): Post abortion Family Planning, Addressing the Cycle of Repeat Unintended Pregnancy and Abortion. International Perspectives on Sexual and Reproductive Health, Alan Guttmacher Institute, Volume 36, Number 1; Pp 44-46.

4. Ahman, E., and Shah, I., ( 2012): New estimates and trends regarding unsafe abortion mortality. International Journal of Gynaecology and Obstetrics; 115 (2): 121-6.

5. Ahmed, A., (2006) : Effect of husband counseling toward female contraceptive methods in Assuit City. Thesis of Fulfillment of Master Degree. Faculty of nursing, Assuit University; Pp: 78-80.

6. Azmat, S., Hameed, W., Ishaque, M., Mustafa, G., and Ahmed, A., (2012) : Post abortion care family planning use in Pakistan. Pakistan Journal of Public Health vol. 2, No. 2: Pp 4-7.

7. Biney, A., (2011) : Exploring Contraceptive Knowledge and use among Women experiencing induced abortion in the greater Accra Region ,Ghana, Regional Institute for Population Studies (RIPS), University of Ghana. African Journal of Reproductive Health; 15(1):37-40.

8. Ceylan, A., Ertem, M., Saka, G., and Akdeniz, N., (2009) : Post abortion family planning counseling as a tool to increase contraception use. BMC Public Health, Department of Public Health, Medical Faculty of Dicle University, Diyarbakir, Turkey, Department of Obstetrics and Gynecology; Pp 17.

9. EDHS (2009) : Hospital admissions resulting from unsafe abortion estimates from 13 developing countries. Egyptian Demographic Health Survey: Pp 1886-1891.

10. Fasubaa, B., (2004) : Impact of post-abortion counselling in a semi-urban town of Western Nigeria. Faculty of Clinical Sciences. Obafemi Awolowo University, Ile-Ife, Nigeria Vol. 24. No. 3; Pp 298-303

11. Ferreira, A., Souza, A., Lima, R., and Braga, C., (2010) : Choices on contraceptive methods in post-abortion family planning clinic in the northeast Brazil. :( 7) Pp 1-5. Bio Med Central Ltd.

12. Glasier, A., and Shabban (2008) : Implantable contraceptives for women: effectiveness, discontinuation rates, return of fertility, and outcome of pregnancies; 63: Pp 42-56.

13. Hassan, S., (2011): Emergency contraception as a backup of Lactational amenorrhea method of contraception. Thesis of Fulfillment of Master Degree. Faculty of Nursing. Assiut University; Pp 79-88.

14. Huntington, D., Hassan, E., Youssef, H., Abdel -Tawab, N., and Nawar, L., (2003) : The Post abortion Caseload in Egyptian Hospitals: A Descriptive Study. Thesis of Fulfillment of Master Degree. International Family Planning Perspectives. Volume 29, Number 3; Pp121-125. 
15. Jackson, A., Rebecca, S., Bimla, E., Lori, F., and Philip, M., (2003): Advance Supply of Emergency Contraception: Effect on Use and Usual Contraception-A Randomized Trial. The American College of Obstetricians and Gynecologists .Vol (102); Pp 8-16.

16. Jones, K., USAID (2007) : Repeat Abortion in the United States, United States Agency for International Development; No.9; Pp 5-7.

17. Langston, A., Rosario, L., and Carolyn, L., (2010): Structured contraceptive counseling-A randomized controlled trial. Division of Family Planning and Preventive Services, Department of Obstetrics and Gynecology, Columbia University Medical Center, New York, USA, Patient Education and Counseling 81: 362-367.

18. Matthew, F., Smith, K., and Mitchell, D., (2008): Contraceptive Effectiveness of Immediate Compared With Delayed Insertion of Intrauterine Devices after Abortion: A Decision Analysis, (C) the American College of Obstetricians and Gynecologists; Pp 1-

19. Murray, C., (2009): Complications of Pregnancy; Pp 622-629, http://www.course ware objects.com.

20. Population Council and Family Health International (2007): Situation Analysis of the Integration of Family Planning Services in Postpartum, Post abortion and Prevention of Mother to Child Transmission Programs in the Dominican Republic; Pp 1-2..

21. Prata, N., Bell, S., Holston, M., Gerdts, C., and Melkamu, Y., (2011) : Factors Associated with Choice of Post-Abortion Contraception in Addis Ababa. Ethiopia, African Journal of Reproductive Health; 15 (3): 51-56.

22. Rasch, V., and Lyaruu, M., (2004) : Unsafe abortion in Tanzania and the Need for Involving Men in Post abortion Contraceptive Counseling. Study .Fam. Plann, 36(4), 301-310.

23. Savelieva, I., John, M., Inna, S., and Longanathan, R., (2003) : Post abortion Family Planning Operations Research Study in Perm, Russia, FRONTIERS Final Report, Washington, D.C.; Population Council. Pp 8-24..

24. Sedgh, G., (2007): Women with an unmet need for contraception in developing countries and their reasons for not using a method, Occasional Report, New York: Guttmacher Institute, No. 37.

25. Shah, A., (2009): Unsafe abortion, Journal of Obstetrics and Gynecology Canada, 31 (12) POP.MID; Pp (1149-1158).

26. Smith, R., USAID (2007): Family Planning Saving Lives. Fourth Edition. United States Agency for International Development .

27. Tilley, I., Shabaan, O., Wilson, M., and Glasier, A., (2009): Breastfeeding and contraception use among women with unplanned pregnancies less than two years after delivery. International Journal of Gynecology and Obstetrics; 105: 127-130.

28. Tripney, J., Schucan, K., Kwan, I., and Kavanagh, J., (2011): The impact of postabortion care family planning counseling and services in low-income countries: a systematic review of the evidence. Technical report. London: EPPI-Centre, Social Science Research Unit, Institute of Education, University of London; Pp 224-226.

29. USAID (2002): Family Planning Prevents Abortion, United States Agency for International Development. POP Briefs.

30. USAID (2004): Issues in Post abortion Care: Scaling-Up Services in Francophone Africa, United States Agency for International Development; Pp 5-7.

31. USAID (2007): Report of the Post Abortion Care Technical Advisory Panel, United States Agency for International Development; Pp (3-5).

32. USAID (2009): GLOBAL POSTABORTION CARE DESK REVIEW, United States Agency for International Development; Pp 45-51. (http://dec.usaid.gov).

33. WHO, Holloway, B., Moredich, C., and Aduddel, K., (2006): OB Peds Notes, Family Planning Options: Nurse's Clinical Pocket Guide. Copyright (C), World Health Organization; Pp 8-15.

34. WHO (2007): Unsafe Abortion/ Global and Regional Estimates of the Incidence of Unsafe Abortion and Associated Mortality, World Health Organization; Pp 1141-1152.

35. WHO (2008): Un Safe Abortion, Global and regional estimates of the incidence of unsafe abortion and associated mortality in 2008, sixth edition, World Health Organization; Pp 1-16. 